\title{
LA BOCA DE PANTAGRUEL: UNA IMATGE DE RABELAIS HERETADA DE LA FICCIÓ LLUCIANESCA
}

\author{
DAVID SOLÉ GIMENO \\ Universitat de Barcelona \\ dsoleg@ub.edu \\ ORCID: 0000-0002-0184-0664
}

RESUM

Llucià de Samòsata influí destacablement en diversos autors del Renaixement com François Rabelais. El metge francès sabé extreure del polèmic escriptor de la Segona Sofística tota la seva essència més satírica i mordaç així com també l'afició (sempre amb un rerefons crític) a les narracions de viatges. Una de les analogies que, en aquest darrer aspecte, evidencien estudiosos de l'obra del francès i del de Samòsata és la que existeix entre la descripció de l'interior de la boca del gegant Pantagruel en el seu Gargantua i Pantagruel i la de la balena que habiten els protagonistes dels Relats Verídics. El propòsit d'aquest article consisteix a analitzar els paral-lels entre ambdós episodis, tot justificant com Rabelais fa efectiva una vívida ficció amb l'ús de diversos procediments heretats de Llucià.

PARAULES CLAU: Llucià de Samòsata, François Rabelais, tradició clàssica, ficció, intertextualitat, vitalisme.

\section{THE PANTAGRUEL'S MOUTH: A RABELAIS'S IMAGE INHERITED OF THE LUCIAN'S FICTION}

\section{ABSTRACT}

Lucian of Samosata has clearly influenced some Renaissance authors, François Rabelais among them. This French physician knew how to get the most satirical and sarcastic essence of the Second Sophistic's author, and also his interest in journey stories, always with a critical point of view. Scholars usually emphasize the analogy between Rabelais' description of Pantagruel's mouth in Gargantua and Pantagruel and Lucian's True Stories' episode on main characters' stay inside a wale. The aim of this paper is to analyze the similarities of these two episodes and try to explain how Rabelais makes his fiction vivid using the same narrative strategies we can find in Lucian's work.

KEYWORDS: Lucian of Samosata, François Rabelais, classical tradition, fiction, intertextuality, vitalism. 
Una minsa aportació de tradició clàssica dedicada al tan estimat Dr. Pau Gilabert.

Si bé és evident que el públic - lector o oient - de les narracions ha anat variant amb el pas dels segles, una ficció relatada amb vivesa no deixa indiferent ningú, sigui de l'època que sigui. Un viatge per terres llunyanes i desconegudes però, alhora, volgudament realistes a ulls de la pròpia imaginació sempre ha sigut agraït per un receptor més antic o més modern. Llucià de Samòsata i François Rabelais comparteixen el savoir faire d'una ficció intensa i versemblant; irreal i, alhora, crítica amb el món que els envolta, essència de llur fil narratiu.

\section{LA NARRACIÓ FICTÍCIA DE LLUCIÀ EN LA SEVA POSTERITAT}

Amb un interès desigual durant els períodes literaris subsegüents, els escrits de Llucià quedaren relativament oblidats fins ben entrat el Renaixement. ${ }^{1}$ Fou durant aquesta etapa quan diversos autors s'inspiraren considerablement en algunes de les seves originals temàtiques argumentals, el seu to irònic i també el seu vívid estil literari. En aquest sentit, trobem obres com la de Thomas More o la de François Rabelais, ${ }^{2}$ entre d'altres. ${ }^{3}$ Efectivament, cal destacar un element comú de tots ells: la fixació en la temàtica dels viatges imaginaris com els que ja s'havien narrat, segles enrere, en l'enlairament d'Icaromenip o, més especialment, en el periple - amb un llarg recorregut aeri inclòs - dels Relats Verídics ${ }^{4}$ per part de Llucià.

\section{FRANÇOIS RABELAIS, «LE LUCIEN FRANÇAIS»}

Centrant-nos aquí a parlar sobre els paral-lels existents entre una aventura de Gargantua i Pantagruel ${ }^{5}$ de François Rabelais i una altra de $V H$ de Llucià, haurem de tenir en compte algunes de les influències que el francès del Renaixement

\footnotetext{
${ }^{1}$ Cf. Chambry, Billault i Marquis (2015: 22).

2 Sobretot, Gargantua i Pantagruel, monumental obra en la qual se centra el present estudi. Les pàgines del pròleg de Gargantua i del breu capítol de Pantagruel que aquí anirem citant corresponen, respectivament, a l'edició de Plattard (1946a: 5-6 i 1946b: 160-165).

${ }^{3}$ Reberen clares influències de l'autor de Samòsata personalitats com Savinien Cyrano de Bergerac (amb l'obra Histoire comique des États et Émpires de la Lune, 1657), Jonathan Swift (amb el seu Gulliver's Travels, 1726) o Ludvig Holberg (amb la novel-la còmica Nicolai Klimii iter subterraneum, 1741).

${ }^{4}$ D'ara endavant, designarem aquesta obra VH (i. e. Verae Historiae). Les traduccions dels passatges que reproduïm s'han extret de Berrio (1995).

${ }^{5}$ Es tracta de la que correspon al capítol XXXII -encapçalat amb el títol «Comment Pantagruel de sa langue couvrit / toute une armée, / et de ce que l'auteur vit dans sa bouche»- del primer llibre que va ser confegit, Pantagruel.
} 
prengué del grec-romà de Samòsata. En efecte, un dels màxims estudiosos de la tradició clàssica com és Gilbert Highet es posiciona a favor de l'estreta relació entre ambdós autors tot afirmant que Llucià fou, per a Rabelais, no només «his favourite writer» sinó també «his spiritual comrade». ${ }^{6} \mathrm{D}^{\prime}$ altra banda, el gran monògraf de del segle XX, Jean Plattard, afirmà, ras i curt, que, per a llurs contemporanis, l'autor renaixentista era «el Llucià francès». ${ }^{7}$

Sigui com sigui, si Llucià fou un personatge veritablement culte de la seva època -instruït en el marc de la paideía de la Segona Sofística-, François Rabelais també ho va ser de la seva. L'autor francès, assedegat de saviesa tant o més que el samosatenc, fou un monjo de l'orde franciscana $-i$, més tard, de la benedictina - que devorà molts llibres. Finalment, havent deixat de banda els hàbits religiosos, es formà en medicina i es dedicà, paral-lelament, a escriure almanacs i a restaurar velles cròniques. A partir del format i de la naturalesa d'aquests documents, en recreà d'altres però sempre incloent-hi part de la seva experiència personal i intel-lectual, amanida amb ficció, crítica i, sobretot, vitalisme. Així doncs, tenint en compte aquesta sèrie de fonaments teòrics $i$ biogràfics ${ }^{8}$ és com entenem que Rabelais escrigué la monumental obra Gargantua i Pantagruel, dividida en cinc llibres.

És evident que, en la seva àmplia formació lectora, Rabelais havia entrat en contacte i s'havia familiaritzat amb el text de Llucià. Mutatis mutandis, l'estructura i la temàtica dels llibres quart i cinquè, ${ }^{9}$ per exemple, es troben directament inspirades en $V H$. Rabelais, entre d'altres aspectes, hi tracta la intenció - que ja té uns precedents indiscutibles a Llucià - de satiritzar les narracions de viatges. En efecte, el francès ironitza sobre l'esquema geogràfic del New World, unes descripcions que abundaven sovint en boca dels primers viatgers a les terres americanes. És aquest un dels molts aspectes amb què l'autor de la França renaixentista - seguint el romà de Samòsata - teixeix un rerefons crític de l'obra, cosa que ja manifesta en el pròleg. ${ }^{10}$ Així mateix, un dels propòsits principals de

${ }^{6}$ Cf. Highet (1949: 184-185): His [sc. Rabelais] favourite writer was Lucian, the laughing Greek sceptic of the later Roman empire, whose work also influenced Erasmus's Praise of Folly and More's Utopia. [...] Lucian was his spiritual comrade, sharing with him the laughter which delights without condemning.

${ }^{7}$ Cf. Plattard (1967: 213): «[...] pour tous, amis ou détracteurs, il est le Lucien français».

8 Explicats detalladament a Lanson (1956: 94 i ss).

${ }^{9} \mathrm{El}$ fet que aquests llibres es considerin pòstums i d'una autoria qüestionable no anul·la, a parer nostre, la tesi principal de la influència llucianesca.

${ }^{10} \mathrm{Cf}$. Gargantua, Prologue de l'Auteur (Plattard 1946a: 5-6): A l'exemple d'icelluy vous convient estre saiges, pour fleurer, sentir et estimer ces beaulx livres de haulte gresse, legiers au prochaz et hardiz à la rencontre; puis, par curieuse leçon et meditation frequente, rompre l'os et sugcer la sustantificque mouelle $-c^{\prime}$ est à dire ce que j'entends par ces symboles Pythagoricques - 
la narració de Llucià és un exercici de crítica literària dedicat als seus il·lustres lectors. ${ }^{11}$

Per tant, ambdós autors presenten uns elements propis de la ficció novel-lesca evidents que serveixen per vestir allò que és - com diu Rabelais inspirant-se en una expressió mística - «el moll de l'os» (la sustantifique mouelle), és a dir, l'intrínsec ingredient principal al voltant del qual girarà el fil argumental. Per a Llucià, les víctimes consistiran, sobretot, en els autors de les obres gregues que ell mateix considerava sobre prodigis i fantasia i, en el cas de Rabelais, ho serà la societat coetània a ell mateix.

\section{GARGANTUA I PANTAGRUEL IMPREgNADA DE LLUCIANISME}

Si bé els paral-lels llucianescos són més evidents en els dos darrers llibres de Gargantua i Pantagruel - un viatge fictici ple d'aventures-, tampoc hem de menysprear la influència que reberen el primer i segon llibres Pantagruel i Gargantua. ${ }^{12}$ A més, com comentarem més endavant, l'énergie ${ }^{13}$ que usa per a descriure moltes de les situacions que ens presenta podria ser equiparable a l'enárgeia de Llucià present en les seves abundoses descripcions retòriques (ekphráseis) o les de les circumstantiae de la narració, vívides i sovint sensorials. ${ }^{14}$

Tenint en compte aquests aspectes, comentarem, a continuació, diversos paral·lels del capítol en el qual Alcofribas veu el món que hi ha dins la boca del gegant Pantagruel i el passatge-frontissa dels dos llibres de $V H$, en el qual els protagonistes exploren les contrades existents a l'interior d'una enorme balena.

\footnotetext{
avecques espoir certain d'être faictz escors et preux à ladicte lecture; car en icelle bien aultre goust trouverez et doctrine plus absconce, laquelle vous revelera de très haultz sacrements et mysteres horrificques, tant en ce que concerne nostre religion que aussi l'estat politicq et vie oeconomicque.

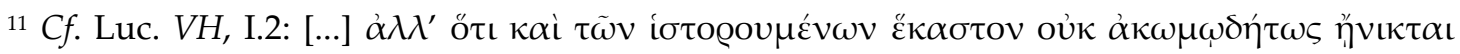

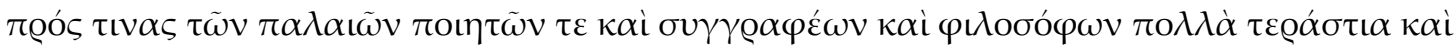

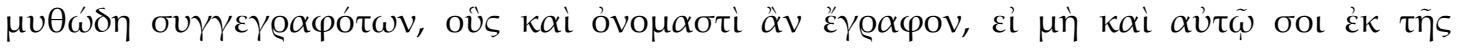
$\alpha \dot{\alpha} \alpha \gamma \nu \omega \omega \sigma \varepsilon \omega \varsigma$ $\varphi \alpha v \varepsilon \tilde{\tau} \sigma \theta \alpha \mathrm{\iota} \varepsilon \ddot{\mu} \mu \varepsilon \lambda \lambda \mathrm{ov}$. «[...] també [sc. els captivarà] el fet que cadascun dels episodis faci al-lusió, amb una certa voluntat caricaturitzadora, a poetes, prosistes i filòsofs del passat que han escrit obres sobre prodigis i de fantasia. Podia haver-ne citat els noms, però he cregut que vosaltres mateixos els anireu descobrint a partir de la lectura».

${ }^{12}$ Fou en aquest mateix ordre cronològic que foren compostos.

${ }^{13}$ Característica pròpia de Rabelais i d'altres autors del Renaixement.

${ }^{14} \mathrm{Cf}$. Bompaire (1958: 707-744).
} 
Diversos estudiosos de tradició clàssica en general ${ }^{15}$ i de Llucià de Samòsata ${ }^{16} \mathrm{i}$ François Rabelais ${ }^{17}$ en particular afirmen que el passatge del francès presenta reminiscències, influències $\mathrm{o}$, directament, està inspirat en l'episodi del cetaci de $V H$.

\subsection{Un context de descobriments}

A priori, segons Christopher Robinson, ${ }^{18}$ en l'època de Rabelais hi havia una gran efervescència per la temàtica dels viatges ficticis des que es descobrí el New World, uns quaranta anys enrere. Per aquest motiu, no sembla inversemblant trobar una referència a aquest «nou món», justament quan Alcofribas -que representa Rabelais $-{ }^{19}$ fa el primer cop d'ull al paisatge intern de la boca de Pantagruel. És una reacció similar a la que experimenta Llucià, després de la seva entrada turbulenta a la balena, però amb aquest element contemporani del segle XVI afegit. Ambdós autors recreen una fotografia geogràfica de l'indret:

Pantagruel, XXXII: Mais, ô dieux et deesses, que veiz je là? Juppiter me confonde de sa fouldre trisulque si j'en mens. Je y cheminoys comme l'on faict en Sophie à Constantinoble, et y veiz de grans rochiers, comme les monts des Dannoys, je croy que c'estoient ses dentz, et de grands prez, de grandes forestz, de fortes et grosses villes, non moins grandes que Lyon ou Poictiers.

[...] -Jesus! dis je, y a il icy un nouveau monde? -Certes, dist il [sc. un bon home qui plantoit des choulx], il n'est mie nouveau; mais l'on dist bien que, hors d'icy, a une terre neufve où ilz ont et Soleil et Lune, et tout plein de belles besoignes; mais cestuy cy est plus ancien. ${ }^{20}$

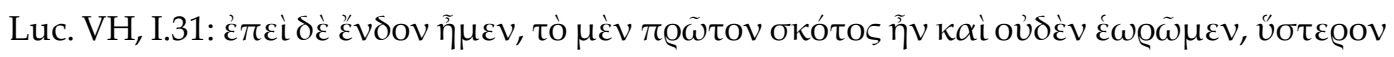

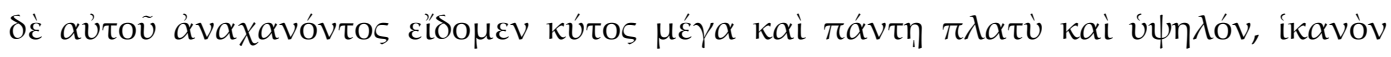

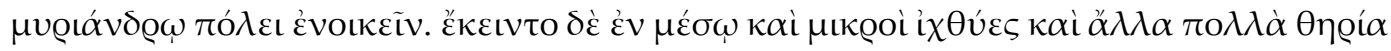

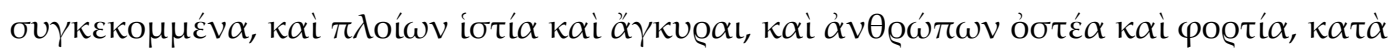
$\mu \varepsilon \dot{c} \sigma o v \delta \dot{\varepsilon} \kappa \alpha \grave{i} \gamma \tilde{\eta} \kappa \alpha \grave{i} \lambda$ ó

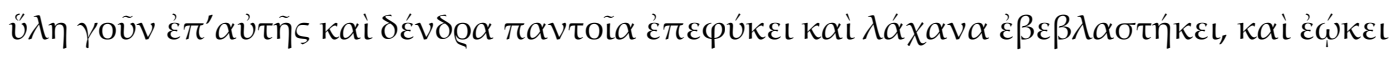

${ }^{15}$ Cf. Robinson (1979: 134) i Auerbach (1996: 245-264).

${ }^{16}$ Cf. Chambry, Billault i Marquis (2015: 24); Vives Coll (1959: 12) i Berrio (1995: 22). En canvi, Alsina (1981: 61) destaca com Rabelais beu de Llucià però no esmenta l'episodi que estem comentant.

${ }^{17}$ Cf. Plattard (1967: 210-211).

${ }^{18}$ Cf. Robinson (1979: 134).

${ }^{19} \mathrm{Cf}$. De la mateixa manera que el $\Lambda$ ovkı $\alpha$ vó $\varsigma$ protagonista de $V H$ representaria el propi autor de Samòsata.

${ }^{20}$ Cf. Plattard (1946b: 161-162). 


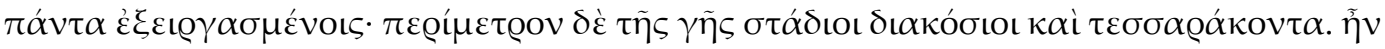

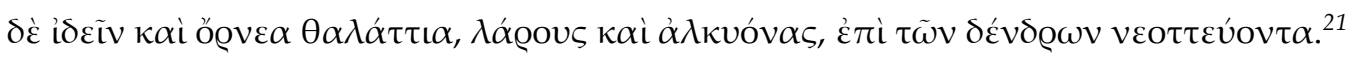

Hem de tenir en compte que les aventures de Llucià es desenvolupen més enllà de les Columnes d'Hèracles ${ }^{22} \mathrm{i}$ això obre la possibilitat a l'autor de crear un món del tot fictici ja que, pel que sabem, l'Oceà extern encara no havia sigut explorat pels grecs. En efecte, tal com apunten Georgiadou i Larmour (1998: 312) sobre la Geografia d'Eratòstenes, l'espai marítim és un escenari del tot

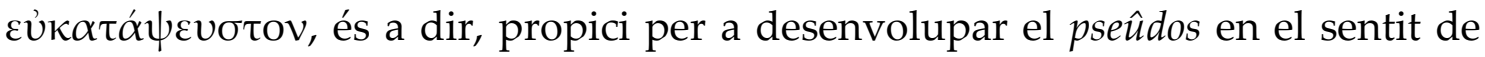
«ficció». Llucià, que a VH deixa anar una ironia maliciosa indubtable, l'aprofita per crear una sèrie de mons fantàstics i aparentment irreals; un d'aquests seria, sens dubte, l'habitatge d'éssers monstruosos que constitueix l'interior del cetaci on es troben els protagonistes. ${ }^{23}$ A la boca de Pantagruel, en canvi, ens ubiquem en un món no només socialment i sinó també econòmicament ben desenvolupat, que no és res més que una recreació de la França coetània a l'autor. Tanmateix, l'element del descobriment del New World - mutatis mutandis, doncs, del viatge «real» més enllà de les Columnes d'Hèracles - ja es troba desenvolupat, a diferència, evidentment, de catorze segles enrere. Així doncs, la paròdia rauria en el fet que aquest indret tan increïble com és l'interior de la boca d'un gegant - un personatge que és indubtablement fictici! - equivalgui al New World, una «realitat» que sovint era qüestionada i caricaturitzada socialment.

Amb tot, en aquest punt, ens hem de fixar en el possible desenvolupament d'una paradoxa epistemològica: des de dins de la boca, hom diu que el «nou món» és a fora, alhora que Alcofribas, que ve de l'exterior, es pregunta si el nou món és el de dins. Amb tot això, es percep satíricament una confusió amb la qual hom es qüestiona, finalment, quin és aquest New World - si és que de debò

\footnotetext{
${ }^{21}$ «Un cop a dins, de primer tot era fosc i no vèiem res, però després, quan la balena obrí la boca, vam veure una gran cavitat plana pertot arreu i elevada, capaç d'acollir una ciutat de deu mil homes. Al mig hi havia, atrapats, peixos grans i petits, i moltes altres bèsties, veles i àncores de naus, ossos humans i mercaderies; a la zona del mig, fins i tot, hi havia terra i muntanyes, formades, a parer meu, per la sedimentació del fang que s'empassava la balena. En aquest tros de terra, s'hi havia fet un bosc i arbres de tota mena, hi havien crescut enciams i semblava tota conreada. El perímetre de l'illa era de dos-cents quaranta estadis. També s'hi podien veure ocells marins - gavines i alcions concretament-, que feien niu als arbres».

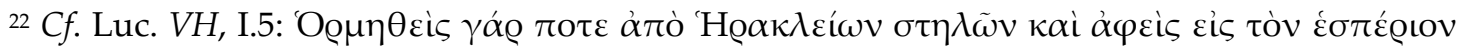

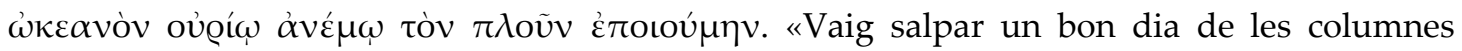
$\mathrm{d}^{\prime}$ Hèracles amb vent favorable, rumb a l'Oceà Occidental».

${ }^{23}$ A més de l'espai de la balena, els protagonistes de $V H$ visiten altres indrets insòlits com la terra d'uns éssers híbrids mig dones i mig vinyes (cf. Luc. VH, I.7-8), la Lluna (cf. ibid., I.10-27), una illa de formatge envoltada d'un mar de llet (cf. ibid., II.3), l'Illa dels Benaurats (cf. ibid., II.528), l'Illa dels Somnis (cf. ibid., II.32-35), etc.
} 
existeix o és tal com descriuen els viatgers del moment - i quin és el món que ja ha «existit» sempre. ${ }^{24}$ Fent aquesta combinació, Rabelais potser recrea, en part, la paròdia de la caverna platònica que fa Llucià tot posant en paral-lel la metàfora de Plató amb la balena de $V H .{ }^{25}$ I és que, amb això, Llucià es planteja la possibilitat que la balena sigui l'interior de la caverna; de fet, en el text grec, una sèrie d'harmonies imitatives recrearien el paisatge d'aquest món intern. ${ }^{26} \mathrm{El}$ món de fora, el que és suposadament «real», és encara més irreal quan els protagonistes de $V H$ contemplen una lluita entre una sèrie de personatges inversemblants (precisament, gegants!) i és en aquell instant quan dubten de la realitat de dins i de la de fora. En definitiva, l'escriptor francès ha sabut copsar la manera com Llucià posa en escena la fantasia més salvatge, que es troba recolzada en una simulació del realisme: en aquest cas, un plantejament epistemològic sobre la realitat i la ficció.

\subsection{El paral·lel de dues vívides ficcions}

Més enllà del rerefons crític o simbòlic - la sustantifique mouelle - que podria constituir aquesta boca gegantina, trobem una sèrie d'aspectes formals $i$ descriptius que evidencien paral-lels d'una vívida ficció entre el breu capítol de Rabelais i el llarg relat del cetaci de Llucià. Ambdós autors usaren una sèrie de procediments per crear una ficció vívida que no resultés tan llunyana al lector, tot fent-lo més partícip dels mons imaginaris narrats. Tot resseguint el fil argumental del capítol de Rabelais, comentarem la plausibilitat d'aquest fet.

Contextualment, abans d'entrar a l'assalt dels Almirodes (els «Salats», seguint l'etimologia grega), un cop ja pacificada la terra dels Dipsodes (els «Assedegats»), sorprèn una pluja a Pantagruel i tot el seu exèrcit. El gegant, traient només la meitat de la seva enorme llengua, els aixopluga, diu Rabelais, «comme une geline faict ses poulletz», ${ }^{27}$ una comparació segurament popular que, almenys per la quotidianitat que aporta, apropa la ficció que suposa

\footnotetext{
${ }^{24}$ Aquesta confusió és recurrent no només a Rabelais o a Llucià sinó també, per exemple, a l'obra de Savinien Cyrano de Bergerac Histoire comique des États et Émpires de la Lune (1657) on, després de produir-se una sèrie d'ascensos i descensos de la terra a la lluna i viceversa, hom no acaba de saber ben bé on es troba.

25 Seguint l'estudi de Ní Mheallaigh (2014: 227-230).

${ }^{26}$ A Luc. VH, I.38, es pot percebre auditivament una cadena fònica formada per una successió de sons vocàlics /e/ i /o/ (breus i llargs) que evocarien l'eco de la cavitat del cetaci justament

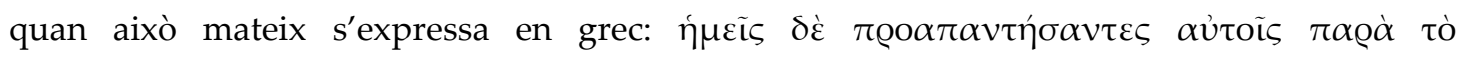

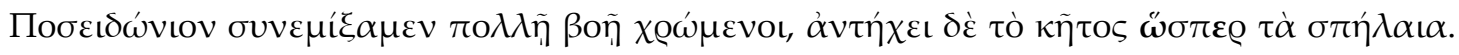
«Nosaltres avançàrem les nostres posicions i, vora el santuari de Posidó, vam començar la barreja fent una cridòria eixordadora, de manera que la balena ressonava com una caverna». ${ }^{27}$ Cf. Plattard (1946b: 161).
} 
l'enorme llengua a la realitat. Alcofribas, com que no té lloc sota la llengua, hi puja i la recorre caminant durant unes exagerades dues llegües $(10 \mathrm{~km}$ !) fins entrar a la boca de Pantagruel. Aquesta hipèrbole numèrica ridiculitza clarament la imatge relatada. Els nombres exagerats també són presents a Llucià: quan els navegants volen sortir de la balena, per exemple, la perforen cinc estadis ${ }^{28} \mathrm{i}$, tanmateix, no en poden sortir. Aquestes exageracions actuen, en ambdues obres, amb una certa comicitat; creen, en efecte, una imatge que trastoca la imaginació de llurs lectors:

Pantagruel, XXXII: Doncques le mieulx que je peuz montay par dessus, et cheminay bien deux lieues sur sa langue, tant que je entray dedans sa bouche. ${ }^{29}$

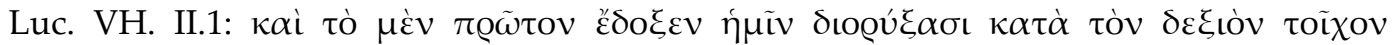

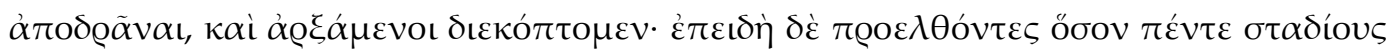

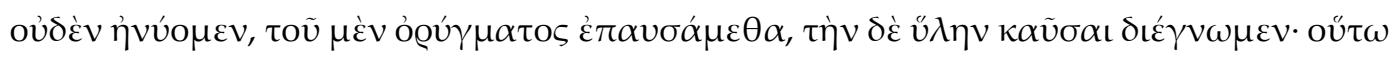

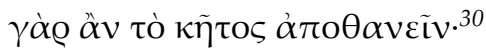

En entrar a la boca de Pantagruel, Alcofribas hi veu, del tot sorprès, un món sencer. Hi contempla muntanyes (que són les seves dents), prats, boscos, ciutats enormes i també ocells! Plattard (1967: 210) considera aquestes aus com un dels principals indicis de la influència llucianesca: «les pigeons qui prenant la bouche de Pantagruel pour un colombier, y entrent à pleine volée, à chaque bâillement, comme les mouettes et les alcyons dans la gueule du cétacé». Aquesta imatge de

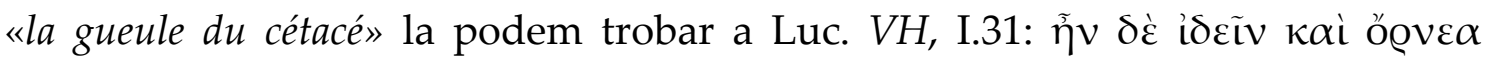

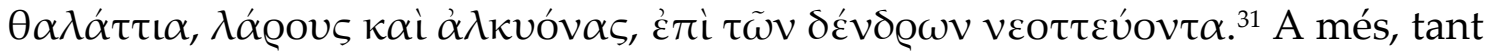
els habitants de la boca gegantina ${ }^{32}$ com els de la balena ${ }^{33}$ viuen, d'alguna manera, a partir de la caça d'aquestes aus.

Tot seguit, ens trobem amb una escena ben corrent i quotidiana: Alcofribas topa amb un home que, amb tota la parsimònia que caracteritza els camperols, es troba plantant cols en aquelles terres: «Le premier que y trouvay ce fut un bon

\footnotetext{
${ }^{28}$ És a dir, gairebé un quilòmetre.

${ }^{29}$ Cf. ibid.

30 «D'entrada, decidírem escapar-nos perforant la banda dreta, i ens vam posar a fer-ho. Tanmateix, després d'avançar vint estadis sense cap resultat, vam abandonar la perforació i vam resoldre incendiar el bosc, pensant que, d'aquesta manera, la balena moriria».

31 «També s'hi podien veure ocells marins - gavines i alcions concretament-, que feien niu als arbres».

${ }^{32}$ Cf. Plattard (1946b: 162): «Or, en mon chemin, je trouvay un compaignon qui tendoit aux pigeons, $[\ldots]$ ».

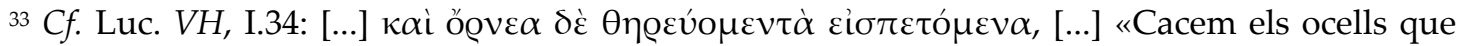
entren volant $[\ldots] »$.
} 
home qui plantoit des choulx». ${ }^{34}$ Aquesta imatge és l'altre indici que Plattard (ibid.) també considera primordial per entendre la relació de Rabelais amb el samosatenc en aquest passatge: «et la rencontre du vieillard qui plante des choulx». I és que Llucià, paral-lelament, una de les coses que es troba en entrar a la balena és, també, una casa de pagès, al costat de la qual Escíntar i el seu fill conreen un hort:

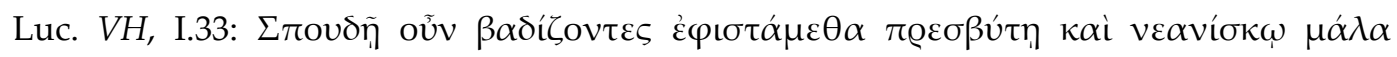

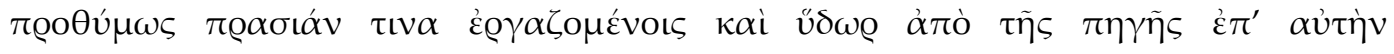

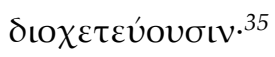

L'agricultor de Rabelais comenta que fa mercat amb una ciutat que es troba més a l'interior. Aquest nucli urbà té un nom d'una lògica irreprotxable pel que fa a la seva situació geogràfica: «Asfàrag». ${ }^{36} \mathrm{El}$ procediment llucianesc de la lògica indiscutible, gairebé científica, per tal de presentar una ficció plausible és aquí present. A la balena, per exemple, trobem un temple de la divinitat marítima per

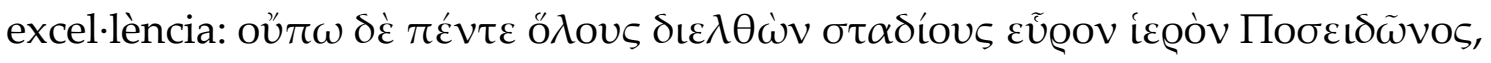
$[\ldots] .{ }^{37}$ Rabelais, doncs, bateja una ciutat amb el nom de «gola» pel fet que es troba en el mateix indret corporal del gegant Pantagruel. Així doncs, ens trobem, en ambdós casos, amb una metonímia de caire topogràfic. A més, l'obra francesa fa coneixedors als lectors de la presència de dues altres poblacions que s'aixequen gola vall i que s'anomenen, literalment, «Laringes» $\mathrm{i}$ «Faringes». Amb tots aquests elements, conjuminats amb d'altres símils geogràfics com Constantinoble, Lyon, Poitiers o les muntanyes daneses (que són, com hem vist, les dents de Pantagruel), Rabelais fa que no resulti tan llunyana tota la ficció al lector, ja que l'ubica en un espai proper i conegut.

Els dos municipis de les contrades més profundes de la boca es troben afectats per una gran pesta: la causa d'aquesta catàstrofe és explicada d'una manera científica o frívolament lògica per part d'Alcofribas. Aquest dedueix, doncs, que la pesta deu tractar-se d'una simple exhalació del pudent alè de Pantagruel, el qual havia menjat una forta salsa d'all, dies enrere:

Pantagruel, XXXII: -Elle a, (dist il), nom Aspharage, et son christians, gens de bien, et vous feront grande chere.

\footnotetext{
${ }^{34}$ Cf. Plattard (1946b: 162).

35 «Deduírem, doncs, que hi havia una casa de pagès. Acceleràrem, per tant, la marxa, i ens trobàrem davant d'un vell i d'un vailet que treballaven amb molt d'afany un hort i canalitzaven l'aigua que brollava d'una font».

${ }^{36}$ En efecte, $\dot{\alpha} \sigma \varphi \alpha ́ \varrho \alpha \gamma o \varsigma$ vol dir «gola».

${ }^{37} \mathrm{Cf}$. Luc. VH, I.32: «Encara no havíem recorregut cinc estadis quan vam descobrir un santuari de Posidó [...]».
} 
[...] A quoy me dirent que c'estoit en Laryngues et Pharyngues, qui sont deux grosses villes telles que Rouen et Nantes, riches et bien marchandes, et la cause de la peste a esté pour une puante et infecte exhalation qui est sortie des abysmes depuis n'a guerres, dont ilz sont mors plus de vingt et deux cens soixante mille et seize persones despuis huict jours.

Lors je pensé et calculé, et trouvé que c'estoit une puante halaine qui estoit venue de l'estomach de Pantagruel alors qu'il mangea tant d'aillade, comme nous avons dict dessus. $^{38}$

A més, es comenta que han sigut moltes les víctimes per causa d'aquesta fetor malaltissa. Concretament, es parla de 2.260.016 persones, ni una més ni una menys, cosa que representa, novament, una exageració numèrica. A propòsit de la descripció d'aquest ambient sensorialment fètid, val la pena fer referència a una ocasió del capítol de la balena de Llucià, on també es reprodueix una olor desagradable quan els protagonistes intenten cremar el monstre marí per dins i

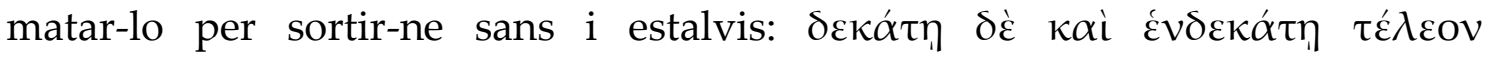

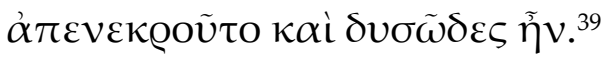

Després, el protagonista del capítol de Rabelais visita les dents de Pantagruel, que estan revestides d'uns indrets preciosos, amb prats, vinyes, casetes i camps; uns espais, doncs, realment idíl-lics que recordarien, en certa manera, 1'Illa dels Benaurats descrita per Llucià. ${ }^{40} \mathrm{El}$ mateix menjar que engoleix el gegant és l'aliment que nodrirà el personatge que ocupa la seva boca, vingut de l'exterior: es tracta d'un fet que respon, una altra vegada, a una lògica fictícia evident.

\subsection{Un vitalisme de Rabelais influït pel samosatenc?}

Finalment, Alcofribas dorm en un indret on cobren els qui dormen més. Veiem com coexisteixen contínues evocacions (fins i tot, podríem dir, elogis) al menjar, al beure i al dormir, que equivalen a la ideologia més pura de Rabelais, és a dir, l'amor a la vida i l'entrega als plaers. En definitiva, es tracta de l'esperit més vitalista de l'autor del Renaixement francès, característica que, potser, compartia amb Llucià, l'obra del qual també té nombroses referències a l'acte de menjar, de

\footnotetext{
${ }^{38}$ Cf. Plattard (1946b: 162-163).

${ }^{39}$ Cf. Luc. VH, II.1: «El desè i l'onzè dia ja era quasi mort [sc. el cetaci] i feia pudor».

${ }^{40}$ Cf. ibid. II.2 i ss.
} 
beure $^{41}$ i també al de dormir. ${ }^{42}$ Tanmateix, com que resulta realment difícil fer una aproximació mínimament encertada del caràcter de l'escriptor de Samòsata, ${ }^{43}$ no podem fer gaire més que limitar-nos a formular aquesta hipòtesi.

\subsection{Mentiders, tots dos}

Per acabar d'arrodonir-ho tot, cal comentar la presència, en aquest capítol, d'una possible reminiscència a un dels punts més conflictius de $V H$. Rabelais, en el seu paper d'Alcofribas, ens amolla una mentida pietosa: diu que ha escrit un llibre sobre els pobles que habiten l'interior de la gola de Pantagruel, que es titula Histoire des Gorgias. ${ }^{44}$ Aquest fet deixa el lector en estat d'intriga, tal com el provocador final de $V H$, en el qual Llucià anuncia que, de la resta de pobles que ha visitat en el seu viatge, en parlarà en els llibres «següents»:

Pantagruel, XXXII: Là commençay penser qu'il est bien vray ce que l'on dit que la moytié du monde ne sçait comment l'autre vit, veu que nul avoit encores escrit de ce pais là, auquel sont plus de XXV royaulmes habitez, sans les desers et un gros bras de mer, mais j'en ay composé un grand livre intitulé l'Histoire des Gorgias, car ainsi les ay je nommez parce qu'ilz demourent en la gorge de mon maistre Pantagruel. ${ }^{45}$

${ }^{41}$ En el decurs de $V H$, apareixen una sèrie d'éssers ficticis que presenten diversos aliments: els

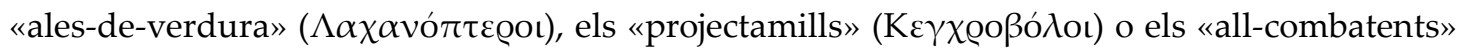

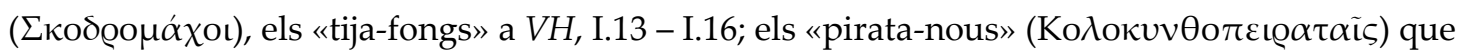
naveguen dins de carbasses a ibid., II.37. A més, comptem amb la presència continuada de referències a àpats i aliments com el vi que banya l'illa de les Dones-Vinyes (cf. ibid., I.7-8) o els làctics de l'illa de Tyros i el mar de llet que l'envolta (cf. ibid., II.3).

${ }^{42} \mathrm{Amb}$ l'estada a l'Illa dels Somnis, on Llucià i els seus companys dormen «feliços» trenta dies i trenta nits (cf. ibid., II.32-35).

${ }^{43} \mathrm{Tal}$ com il-lustren intents de reconstruccions biogràfiques com la de Schwartz (1965), que es basa en les hipotètiques dades que aporten les iròniques obres de Llucià.

${ }^{44}$ Hem de tenir en compte que la paraula 'Gorgias', segons indica Plattard (1946: 213 n. 13), significava élégant en el llenguatge del moment i que, en aquest context, Rabelais la prenia amb el sentit d'«habitants de la gorge». No hem d'oblidar, tampoc, el fet que Gorgias sigui el nom del famós orador grec dels segles $\mathrm{V}$-IV aC, el qual deuria ser reconegut per tot un públic cultivat de l'obra de Rabelais i, d'aquesta manera, ubicaria l'acció narrativa en un context d'ambientació grega.

${ }^{45}$ Cf. Plattard (1946b: 164). 


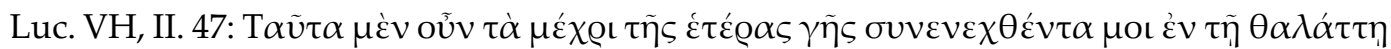

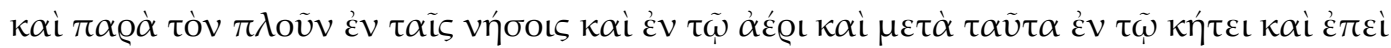

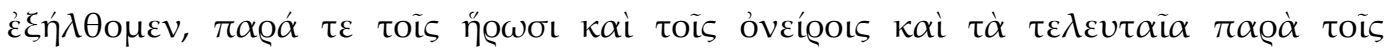

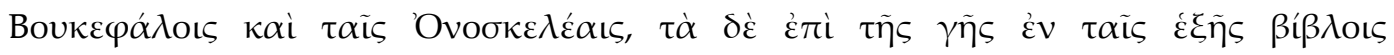
$\delta ı \eta \gamma \dot{\sigma o} \mu \alpha{ }^{4}{ }^{46}$

Sens dubte, es tracta d'uns escrits que, almenys pel que sabem fins ara, són inexistents.

\section{ESPAIS PARAL·LELS, AUTORS VINCULATS}

Com hem vist, Rabelais posa en escena una ficció impregnada de llucianisme. Podem concloure, doncs, que la boca de Pantagruel és una imatge que Rabelais va manllevar de la balena de Llucià. L'escriptor francès rebé una clara influència del de Samòsata en la seva obra no només en termes temàtics sinó també formals, tenint en compte que comparteixen diversos elements com la sàtira contínua i els procediments d'una lògica fictícia: hipèrboles numèriques, metonímies topogràfiques, escenes quotidianes i, en conjunt, l'énergie de les seves descripcions, element que podria correspondre a l'enárgeia de les diverses ocasions d'ekphráseis i caracterització de circumstantiae a VH. Amb tot, doncs, François Rabelais presenta un evident interès per dotar l'espai narratiu d'una essència grega, heretada de Llucià de Samòsata.

\section{BIBLIOGRAFIA}

AUERBACH, E. (1996), Mimesis. La representación de la realidad en la cultura occidental, Ciutat de Mèxic, Fondo de Cultura Económica. (trad. de Villanueva, J. i Ímaz, E., Mimesis: Dargestellte Wirklichkeit in der abendländischen Literatur, Berna, Francke AG. Verlag, 1946).

AlsinA, J. I EsPINOSA, A. (1981), Luciano. Obras, Madrid, Editorial Gredos.

BERrIO, A. (1995), Llucià. Històries Verídiques, Barcelona, Edicions de la Magrana.

BOMPAIRE, J. (1958), Lucien écrivain. Imitation et création, París, Bibliothèque des écoles françaises d'Athènes et de Rome.

Chambry, E., Billault, A. I MARQuis, É. (2015), Lucien de Samosate. Oeuvres Complètes, París, Éditions Robert Laffont.

GeOrgiadou, A. I LARMOUR, D. (1998) «Lucian's Verae Historiae as Philosophical Parody», Hermes, 126, 310-325.

\footnotetext{
46 «Tot això és el que em va passar al mar, a les illes i a l'aire abans d'arribar a l'altre món; després, a dins de la balena i, un cop fora, al país dels herois, al dels somnis i finalment al dels bucèfals i al de les cames d'ase. El que va passar en aquella terra ho explicaré en els llibres següents».
} 
HigheT, G. (1985 [1949]), The Classical Tradition: Greek and Roman Influences on Western Literature, Nova York i Oxford, Oxford University Press.

LANSON, G. I TUFFRAU, P. (1956), Manual de Historia de la Literatura Francesa, Barcelona, Editorial Labor.

Ní Mheallaigh, K. (2014), Reading Fiction with Lucian. Fakes, Freaks and Hyperreality, Cambridge i Nova York, Cambridge University Press.

PlatTARD, J. (1967 [1910]), L'œuvre de Rabelais. Sources, Invention et Composition, París, Librairie Honoré Champion.

PlatTARD, J. (1946a), Gargantua, París, Société Les Belles Lettres.

Plattard, J. (1946b), Pantagruel, París, Société Les Belles Lettres.

ROBINSON, C. (1979), Lucian and his influence in Europe, Londres, Duckworth.

SCHWARTZ, J. (1965), Biographie de Lucien de Samosate, Brussel-les, Latomus.

VIVEs Coll, A. (1959), Luciano de Samosata en España, Valladolid, Secretariado de Publicaciones de la Universidad de la Laguna. 